\title{
Social psychology applied
}

Citation for published version (APA):

Kok, G. (2016). Social psychology applied: Politics, theories, and the future (Valedictorian Lecture). Maastricht University. https://doi.org/10.26481/spe.20160408gk

Document status and date:

Published: 08/04/2016

DOI:

10.26481/spe.20160408gk

Document Version:

Publisher's PDF, also known as Version of record

\section{Please check the document version of this publication:}

- A submitted manuscript is the version of the article upon submission and before peer-review. There can be important differences between the submitted version and the official published version of record.

People interested in the research are advised to contact the author for the final version of the publication, or visit the DOI to the publisher's website.

- The final author version and the galley proof are versions of the publication after peer review.

- The final published version features the final layout of the paper including the volume, issue and page numbers.

Link to publication

\footnotetext{
General rights rights.

- You may freely distribute the URL identifying the publication in the public portal. please follow below link for the End User Agreement:

www.umlib.nl/taverne-license

Take down policy

If you believe that this document breaches copyright please contact us at:

repository@maastrichtuniversity.nl

providing details and we will investigate your claim.
}

Copyright and moral rights for the publications made accessible in the public portal are retained by the authors and/or other copyright owners and it is a condition of accessing publications that users recognise and abide by the legal requirements associated with these

- Users may download and print one copy of any publication from the public portal for the purpose of private study or research.

- You may not further distribute the material or use it for any profit-making activity or commercial gain

If the publication is distributed under the terms of Article $25 \mathrm{fa}$ of the Dutch Copyright Act, indicated by the "Taverne" license above, 


\section{Gerjo Kok PhD}

Faculty of Psychology and Neuroscience

\section{Social Psychology Applied: Politics, Theories, and the Future}

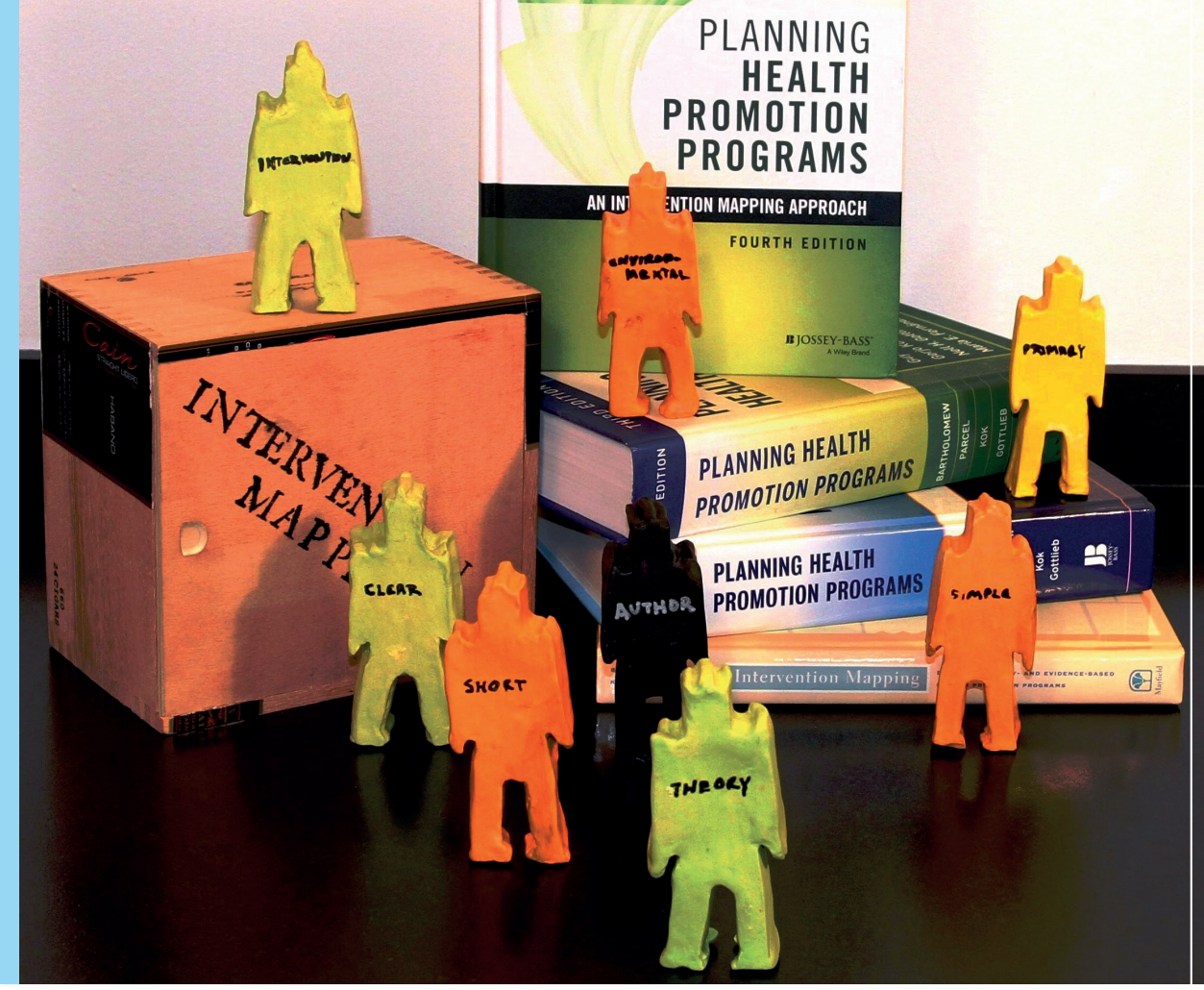



Social Psychology Applied:

Politics, Theories, and the Future 


\section{Colofon}

Design \& print: Canon Business Services, Maastricht

ISBN: 978-90-5681-459-5

NUR: 775

All rights reserved. No part of this publication may be reproduced, modified, stored in a retrieval system or made public without the prior written permission of the author or publisher. 


\section{Social Psychology Applied:}

\section{Politics, Theories, and the Future}

Valedictorian Lecture

Maastricht University, April 8, 2016

\section{Gerjo Kok PhD}

Professor of Applied Psychology in the faculty of Psychology and Neuroscience 
Highly esteemed Rector, ladies and gentlemen,

Politics, Theories and the Future In one of his columns, Jaap van Heerden' describes the Netherlands as "a country of lectures". He also describes the typical Dutch lecture as one in which the lecturer excels in identifying the negative developments in society in general, and in the field of expertise of the lecturer in particular. I admit that it would be easy - and quite pleasant - to fill these 45 minutes with a list of everything that I find below standard, incompetent, irritating, or evil. Without complying with the positive psychology doctrine - which would be on my list - I will instead focus on what I think are positive developments in our field of research and teaching. Of course, as I learned from Hans Philipsen a long time ago, if you are positive about something, you are unavoidably also negative about the opposite. So I will try to describe developments in our work in the area of applied social psychology that I see as positive, without saying too much about the negative counterparts.

Today The title of my valedictory lecture is 'Politics, Theories and the Future'. In relation to the first topic, I will focus on the role of science in politics and on the role of politics in science. I will illustrate both of these roles using the example of so-called fear appeals, as they are applied in the form of scary pictures on packages of cigarettes. I will explain that my solution to problems arising from the interplay between politics and science is two-fold:1) the execution of methodologically appropriate research, and 2) the correct application of theories, which is the second topic in my lecture. In the third and last theme addressed in this talk - the future - I will illustrate how we in Maastricht have contributed to these solutions, and will continue to do so.

\section{Promovendi \& Promotores}

Science is team work. In this presentation, I will mention the names of some of the people that I have worked with, in many different teams, since 1975. There are many more people than I can mention in these 45 minutes, but please be assured that I learned from all of you, and that the work we did had an influence and will continue to do so. 


\section{Politics}

Politics

There is an interesting tension between science and politics. Politicians often claim that their ideas are evidence-based, while scientists try to get the results of their work implemented in political decision making. To provide an example, in this country, the practice of sex education for adolescents is very much in line with the scientific evidence on the effectiveness of sex education ${ }^{2}$. During the early years of AIDS prevention activities, my American colleagues were quite envious about the relatively free reign we had in schools while they were forced, when funded by the government, to comply with the norm of abstinence. All the evidence pointing to the negative effects of abstinence education did not have any effect on US policies?

\section{Scary pictures}

This is not to say that in the Netherlands there is no tension between science and politics. Scientific arguments comprise just one of many factors that determine politicians' behavior, and they are not always given the attention they deserve. In our work, the most obvious example of that tension is the debate about the use of scary pictures on cigarette packaging, an application of what we call fear appeals, which are supposed to stimulate smokers to quit smoking and discourage nonsmokers from starting. I will discuss this example in more detail because it demonstrates nicely how scientific insights are ignored because they are either counterintuitive and/or politically inconvenient. I will describe the theory and evidence related to this issue, our attempts to convince politicians to make decisions based on theory-based evidence, and the resistance we have experienced from within the scientific community.

\section{Theory and evidence}

\section{Scary pictures: Theories and evidence} The reasoning behind the use of scary pictures on packages of cigarettes is the idea that, when people are emotionally confronted with the negative effects of their behavior, they will change their behavior; in this case they will quit smoking. What's more, the scarier the picture, the larger the effect, or so the argument goes. The same reasoning has been applied to other areas such as alcohol and drug education, 
and traffic safety education. The reasoning is simple and intuitive, but wrong. In scientific terms, these scary pictures constitute an example of fear appeals, which are a form of risk communication. As Rob Ruiter and colleagues ${ }^{4}$ so nicely summarized, research into risk communication has a long history, and right from the beginning, theory and evidence has indicated that using scare-tactics could in fact be counterproductive. The theories differ in details, but not in essence, and together they clearly indicate an interaction of four variables that influence behavior change: 1) severity: are there serious consequences of this behavior?, 2) susceptibility: might it happen to me?, 3) responseefficacy: is there something I can do to prevent this?, and 4) self-efficacy: am I confident that I can do that? Severity and susceptibility combine to form a perceived threat. Response-efficacy and self-efficacy combine into efficacy. Without going into too many details, the theory predicts that if severity and susceptibility are both high, people will experience a threat, and want to do something to counter that threat. However, what they do is determined by efficacy: if efficacy is high, they may change their behavior in the suggested direction; if efficacy is low, they may react defensively, for example by ignoring, denying, or rejecting the threat. In relation to our specific example, the theory predicts that when smokers are confronted with scary pictures, both severity, susceptibility - and thus threat - will be high, response efficacy will be clear (quitting ends the threat), but self-efficacy will most probably be very low (most smokers have unsuccessfully tried quitting a number of times). To summarize, the theory predicts that smokers, because their self-efficacy in relation to quitting is low, will react defensively to these scary pictures. In fact, they may actually smoke more in order to deal with the stress.

\section{Scary pictures: Evidence}

There is a certain logic to this theoretical reasoning, but for most people, fear appeals are still the answer to all health promotion challenges. So let us look at the evidence. In order to do this, we first have to decide what kind of evidence we will accept as valid; a very basic but necessary step. The only way to test whether an intervention has a specific effect on a behavior is to apply an experimental design. In an experiment, the intervention is applied in one group, and this group is compared to a group which has received either no intervention or another type of intervention. The assignment of participants into intervention and comparison groups should be based on a random procedure. If the desired outcome constitutes a (change in) behavior, 
in this case quitting smoking, that behavior should constitute the outcome measure. In summary, we have three criteria for correctly applying an experimental design: 1) different interventions or conditions, 2) random assignment of participants to these groups, and 3) behavior as an outcome measure. The good news would appear to be that there are hundreds of publications claiming to have studied the effects of using scary pictures. The bad news is that none of those studies fulfill these three criteria - not one of them. Of course there are reasons for this. First, and in relation to behavior as an outcome measure, quitting smoking is a behavior that we can only take seriously when people have been free from cigarettes for one year (some researchers would say only after two years of non-smoking). Changes in intentions often predict behavior change, but in situations where defensive reactions are likely to occur we do not believe intentions are good predictors of behavior4. It seems clear that finding an acceptable behavioral outcome measure is difficult in this case. Secondly, and in regard to random assignment, scary pictures on cigarette packages are often introduced on a national scale as a policy measure, meaning that there is no way to arrange for an adequate control group. Randomization can be achieved in laboratory studies, but not necessarily in real life situations. It is obvious, then, that randomization is also difficult in this case. Finally, in relation to different interventions - what would be the comparison intervention in this example? Many studies compare the effects of using a combination of written warning texts and scary pictures with using written warnings alone. But that is not so very interesting; even if one fear appeal would have relatively more or less influence than the other, it would not answer our main question about whether fear appeals are more or less effective than alternative interventions, in particular interventions with more focus on self-efficacy.

\section{Meta-analysis}

What to do? Gjalt-Jorn Peters and colleagues 5 carried out a systematic literature review of studies investigating fear appeals - in relation to behaviors other than smoking - that fulfilled the three criteria we mentioned earlier. These studies all compared interventions that varied in the level of manipulated threat and the level of manipulated efficacy. They were all randomized trials, and the outcome measure in each of these studies was behavior. Of all the studies published in the literature, only six could be included in our meta-analysis. What we found was almost exactly what the theory predicted. When the threat was high as 
compared to low, people changed their behavior in the advised direction only when efficacy was high, and not when efficacy was low. In fact, when efficacy was low, the behavior change showed, if anything, an effect in the wrong direction 5 .

\section{Neuroscientific brain research}

While the outcome of this meta-analysis shows that the theory seems to be right, there are still no studies that can confirm or disconfirm the theoretical predictions about the effects of scary pictures on packages of cigarettes specifically. At this point, we turned to neuroscientific brain research. Loes Kessels and colleagues ${ }^{6}$ used EEG to measure smokers' attention for scary and non-scary pictures. Smokers shifted their attention more easily away from the scary pictures but not away from the non-scary pictures. This effect was not found in non-smokers. These studies illustrate that people do react to threatening health information, but in a defensive way: they avoid the information. Again, these data are in line with the theoretical predictions outlined earlier. Our conclusion is that the use of fear appeals, and in particular scary pictures, is not in line with the available theory and evidence about behavior change.

\section{Science and politics}

\section{Dissemination}

It is one thing to publish in scientific journals about the sense or nonsense of fear appeals (which we have done extensively), and quite another thing to translate that work into practical policies. Or, in this case, get politicians and policy makers to listen to you. One way is to publish in journals that do not target researchers but instead target policy makers. We have published about the use of scare-tactics in health campaigns in the Dutch Journal of Health Sciences (TSG, Tijdschrift voor Gezondheidswetenschappen) in 20077, $2012^{8}$ and $2013^{9}$, as well as in the Dutch Journal of Medicine (NTG, Nederlands Tijdschift voor de Geneeskunde) in $2013^{10}$. We have conducted numerous interviews with news media"1. Gjalt-Jorn Peters has a website, http:// fearappeals.com/, which systematically summarizes all our work on fear appeals. We are sure that policy makers at the Ministry of Health are aware of our work. Yet it obviously did not have much of an influence on the recent political decision to make scary pictures on the packaging of tobacco products mandatory. Two factors that confuse 
this issue are 1) that people intuitively believe that fear appeals work and 2) that some researchers still argue in favor of the use of fear appeals in general, and scary pictures in particular.

\section{Counterintuitive}

To expand on the first factor, the idea that fear appeals work is both intuitive and persistent. Gill ten Hoor and colleagues ${ }^{12}$ asked students to predict the outcome of two British studies 13,14 investigating the effects of scary smoking- (or alcohol-) related graphics. Most students thought that more fear would lead to more change. The students were told that the outcomes in fact showed the opposite - that more fear led to less change. Moreover, they read a text explaining the negative effects of fear appeals. Following this, the students were again asked to predict the effects of scary pictures on alcohol- (or smoking-) related behavior. Yet again, they predicted that more fear would lead to more change. Evidence and theory were obviously not enough to counter the intuitive ideas of these students. And we find the same is true of former students who are now politicians or policy makers.

\section{Politics in science}

Politics in science

The second factor confusing the issue is that some of our colleagues in science support the use of fear appeals against all existing evidence. After our publications on the ineffectiveness of scary pictures on packages of cigarettes, we received some emails from colleagues accusing us of working for the tobacco industry. That is of course complete nonsense, but it is also unpleasant and insulting. I don't have to explain in this setting that, both professionally and personally, I find smoking one of the worst behaviors possible. Over an extended period of time, my colleagues and I have contributed to both high-quality research and successful practice in the areas of smoking prevention in various settings $15,16,17,18,19,20,21$. This work continues. In our view, some of our colleagues are so highly committed to promoting health by attacking smoking, that they sometimes lose the scientific distance required in this process. I will illustrate this point with an example of the debate that we had in the literature with Hammond and colleagues. 


\section{Scientific distance: The Debate}

Hammond is not just any researcher. He is the author of the WHO report on the effects of scary pictures on smoking cessation, which resulted in the widespread implementation of graphic pictures on cigarette packages $^{22}$. Politicians who are involved in this issue often refer to his report as the evidence base for their decision. As we mentioned earlier, the empirical evidence behind this decision is not impressive, and specific evidence regarding this policy is not even available. Let us focus on one publication in particular by Hammond and colleagues ${ }^{23}$ - in the American Journal of Public Health - which became the starting point of our debate. Hammond et al. conducted a follow-up study on the introduction of scary pictures in Canada in 2001. Nine months after the introduction of these pictures, they asked smokers if they had stopped smoking and, if so, why. Most quitters reported to have stopped smoking because of the scary pictures. The authors concluded that policy makers "should not be reluctant to introduce these labels". We wrote a letter to the journal, which was rejected for the reason that it was not seen to be "opportune". We then published the letter in the European Journal of Public Health ${ }^{24}$. In it, we argued, amongst other things, that Hammond et al.'s one-group post-test-only design did not allow that conclusion to be drawn, and that they had ignored the available evidence on defensive reactions to fear appeals. Hammond et al. ${ }^{25}$ reacted, which gave us the chance to have the 'last word'26. In response to our first criticism, Hammond et al. countered that experimental studies are impossible to carry out in this kind of situation. While this is true, it does not justify drawing the wrong conclusions from the data available ${ }^{27}$. In relation to our second criticism, Hammond et al. responded: "A recent metaanalysis of the literature on public health communications concluded that 'strong fear appeals and high-efficacy messages produce the greatest behavior change', and found no evidence of any iatrogenic or 'boomerang' effects for strong fear appeals (Witte \& Allen, 2000)." Their first citation is an incompetent and misleading interpretation, and the second statement is simply wrong. Witte and Allen ${ }^{28}$ make it very clear that "practitioners should always ensure that a high threat fear appeal is accompanied by an equally high efficacy (or greater) message" (p. 606). Witte \& Allen also state that "as a fear appeal increases in strength, it produces stronger fear control/defensive responses than danger control responses", and "the more one is defensively resisting a recommendation, the less one is making appropriate changes in line with the message's recommendations" (p. 603). Their final sentence is most illustrative: 
"Fear appears to be a great motivator as long as individuals believe that they are able to protect themselves" (p. 607). The crucial issue here is that the targeted smokers should be confident that they can indeed stop smoking. Most smokers have undertaken several attempts to quit, have failed, and thus feel they cannot stop smoking 29 . Fear-arousing graphic warnings will not help them, even when accompanied by a few words on how to stop. Hammond and colleagues probably meant well, but nevertheless misrepresented the outcomes of the Witte \& Allen meta-analysis in order to justify a health promotion policy that has no foundation in theory or evidence.

In summary, it is not only our politicians who refuse to listen to science; we also have colleagues who misinterpret evidence in order to support their well-intended claims. What's more, we see this not only in relation to smoking studies but in relation to many areas of health promotion. So how do we deal with this phenomenon?

\section{Theories}

There are two solutions:1) the execution of methodologically appropriate research and 2) the correct application of theories. The first is a general prerequisite for science but it is still necessary to explain it over and over in order to prevent inappropriate designs leading to invalid outcomes. The second reflects the essential role of theory in the practical application of scientific evidence. Both solutions are integrated in the Intervention Mapping protocol. In this lecture, I will focus mostly on the second solution: applying theories.

\section{Methodologically appropriate research}

\section{Methodologically appropriate research}

As mentioned earlier, the only way to conclude that an intervention has a specific effect on a behavior is by conducting an experiment. That is a kind of platitude among scientists but nevertheless an essential issue when interpreting the outcomes of intervention studies. As an applied researcher, I am aware of the practical limitations of using experimental designs in real life. We have excellent textbooks on the uses and limitations of quasi-experimental designs, and we have 
creative solutions available for analyzing such designs ${ }^{27,30}$. A further issue of importance is that most applied research on behavior change interventions assesses the effects of the whole intervention, without providing specific information on the effectiveness of the various elements of the intervention, or a combination these elements. We may find an effect of a complex intervention without knowing exactly which components of that intervention were essential for that effect; maybe all of them. This is what it is, but researchers should be very careful in how they interpret study outcomes in terms of cause and effect, bearing in mind the design of the study. Of course lab studies are artificial, and of course real life studies can be richer and more meaningful, but nonexperimental studies simply do not allow conclusions to be drawn in terms of causality. That brings us to the next topic: the essential role of theory in applied social psychological research and practice.

\section{Theories}

Theories

Theories can be defined as formal and abstract statements about a selected aspect of reality ${ }^{31}$. As a consequence of their very nature, theories are always a reduction of reality. That is not a shortcoming but rather a definition. Real-life problems are by definition complex; otherwise they would already have been solved. We need a multi-theories a pproach ${ }^{32}$ to understand and solve real-life problems. From this perspective, applying theory to real life problems can be seen as a jigsaw puzzle with various theories contributing to parts of the solution. The argument that one theory, for example the Reasoned Action Approach, cannot explain all the possible variances in behavior or behavior change is irrelevant. For example, RAA defines itself as a theory about reasoned behaviors, not a theory about automatic behaviors 33 .

"Well, it's just a theory" More precisely, in science, the term theory refers to a well-substantiated explanation of some aspect of the natural world, based on a body of facts that have been repeatedly confirmed through observation and experimentation ${ }^{31}$. Theories must also meet certain requirements, such as the ability to make falsifiable predictions and the production of strong evidence in favor of the theory from multiple independent sources. Lay people may speak about theories in a different way - "Well, it's just a 
theory". Richard Dawkins ${ }^{34}$ responded to such a statement with: "Show me a cultural relativist at 30,000 feet and I'll show you a hypocrite.... The reason you don't plummet into a ploughed field is that a lot of Western scientifically trained engineers have got their sum right." Theories reflect what we currently know about our world.

\section{Generalizability}

Theories can be generalized over groups and across cultures. The specific content will be different but the theory stays the same. Theories can be falsified, of course, but not because of finding specific details that do not fit into the theory. Theories are generic. Some researchers have claimed that: "A compass will not work on Mars" 35 . That is true, but the electro-magnetic field theory will. We have confirmed this perspective in our work with Ph.D. students from many different developing countries $36,37,38,39,40$, and this is work that will continue.

Science is built on theory. Theories are developed through research but in order to be able to generalize research outcomes over various situations, we need a theoretical explanation of the relevant processes. This is one of the premises of Intervention Mapping, the protocol for the planning of theory- and evidence-based behavior change interventions ${ }^{32,41}$.

\section{Intervention Mapping (IM)}

\section{Intervention Mapping: Steps \& Tasks}

The IM protocol describes the iterative path from problem identification to problem solving or reduction. Each of the six steps of IM comprises several tasks, and each of these tasks integrates theory and evidence. The completion of the tasks in each step creates an end product that can be used as a guide for the subsequent step. The completion of all of the steps serves as a blueprint for the design, implementation, and evaluation of an intervention that is based on a foundation of theoretical, empirical, and practical information. The six steps and related tasks of the IM process are as follows: (1) conduct a needs assessment or problem analysis by identifying what, if anything, needs to be changed, and for whom; (2) create matrices of change objectives by combining (sub-) behaviors with behavioral determinants to identify which beliefs should be targeted by the intervention; (3) select theory-based intervention methods that match the determinants into which the identified beliefs 
aggregate, and translate these into practical applications that satisfy the parameters for effectiveness of the selected methods; (4) integrate the practical applications into an organized program; (5) plan for the adoption, implementation, and sustainability of the program in real-life contexts by identifying program users and supporters, and determining what their needs are and how these should be fulfilled; (6) generate an evaluation plan to conduct effect and process evaluations to measure program effectiveness. The key words in $I M$ are planning, research and theory. IM provides a vocabulary for program planning, procedures for planning activities, and technical assistance with identifying theorybased determinants and matching them with appropriate methods for change.

IM is guided by three perspectives ${ }^{32}$ : a multi-theory, an ecological, and a participation perspective. Here, we will focus on the multi-theory perspective which encourages researchers to work with multiple theories. As stated before, one theory will never explain all aspects of a real-life problem. For instance, some theories are especially relevant in terms of identifying the determinants of behavior; others are more useful with regard to choosing and applying behavior change methods. However, at the same time, it must be noted that attempting to integrate various theories into one overarching framework is rarely helpful42. A theory is more than a list of variables; the relationship among the variables often forms the core of the theory. The unique skill of the well-trained behavioral scientist is to link the relevant elements of a given problem to useful theories; even theories that one is not familiar with or has never used before ${ }^{43}$. Ergo, behavioral scientists and their unique expertise are an essential component of an intervention planning team.

Determinants. Changing something requires understanding it first. In the case of behavior change, it is necessary to understand why people engage (or do not engage) in the particular behavior of interest. These reasons are commonly described as cognitions, or emotions, or beliefs, or automatic associations, et cetera. Behavior change methods are designed to change behavior by attempting to change those determinants. However, as determinants are defined generically, they cannot be targeted directly. Instead, behavior change methods target the underlying, more specific, sub-determinants, for example beliefs. It must therefore be clear which sub-determinants are targeted in any behavior change method, and into which determinants these sub-determinants aggregate ${ }^{32}$. 
Behavior change methods. We define theory-based methods, or behavior change methods, as general techniques or processes that have been shown to be able to change one or more determinants of behavior of members of an at-risk group, or of environmental decision-makers. Note that by 'theory-based', we mean that the methods 'have their origins in behavioral and social science theories', and it is not uncommon that evidence supporting a particular method is provided in several theories. The theory explains how this 'mechanism of action' works, and thus testifies as to why we can expect a causal link between application of the method and behavior change. As such, theory-based methods are based on the literature regarding effective behavior change. Such research almost never concerns methods for influencing behavior directly. Rather, in almost all cases, methods are designed to influence determinants such as attitude or self-efficacy, which in turn are thought to influence the behavior in question. Such interventions will always take place in specific populations and environments, meaning that behavior change methods require specific translation into practical applications in order to reach optimal fit41.

Practical applications. We define practical applications as specific translations of theory-based methods for practical use in ways that fit the intervention population and the context in which the intervention will be conducted ${ }^{2}$. Any thorough description of a behavior change application needs to make clear how parameters of effectiveness have been secured.

Parameters for methods. Translating methods into practical applications demands a sufficient understanding of the theory behind the method, especially the theoretical parameters which determine whether the change process is effective or not ${ }^{41}$. The parameters of effectiveness of a theoretical method can be defined as the conditions that must be satisfied in order for the practical application of the method to be effective. In other words, if a practical application embodies a given theoretical method, but violates one or more parameters of effectiveness of that method, it will be less effective, not at all effective, or may even be counterproductive. To illustrate this point, modelling is a strong method, but only when certain parameters are met, for example reinforcement of the modelled behavior. People or environmental decision-makers do not usually imitate behavior simply because a model demonstrates that behavior. Rather, they behave in line with the model only when the model 
includes certain characteristics, such as reinforcement for the particular behavior in question and details of when this reinforcement will occur44. Translating the modelling method into a practical application includes making sure that in the actual execution of the program, from the perspective of the program participants, the model is reinforced. To provide a second example, goal setting can be a very effective method, but only when the goal is challenging as well as achievable for the individual concerned 45 . People often choose goals outside those parameters, for example goals that are set too high or too low. A third example is provided by the implementation intentions method. While very effective when properly applied, any violation of its parameter for effectiveness (a pre-existing intention to perform the behavior) greatly reduces or eliminates this effectiveness ${ }^{46}$. Finally, as we have explained earlier, fear appeals are only effective when the at-risk population has high (self-)efficacy, and they may in fact be counterproductive when efficacy is low ${ }^{5}$. Nevertheless, many expect fear appeals to be effective under all circumstances ${ }^{47,12}$. All theory-based methods have such parameters, which need to be taken into account when translating a method into a practical application. These parameters are generally specified in the theoretical evidence for a given method, which is why this basis in theory is so important. It also illustrates the importance of distinguishing between theoretical methods of behavior change and the practical applications of these methods. An intervention consisting entirely of effective methods of behavior change can fail to show any effect if the application of any of these methods fails to satisfy the parameters of effectiveness. Again, behavioral scientists and their unique expertise are needed in an intervention planning team. Behavior change is not simple 48,49 .

\section{Accreditation of Interventions}

\section{Accreditation of interventions}

In the Netherlands, we have a system for the evaluation and accreditation of health promotion interventions that - unsurprisingly - follows the same kind of reasoning as Intervention Mapping (https://www. loketgezondleven.nl/leefstijlinterventies/erkenningstraject). Program planners can get their interventions evaluated on several dimensions: quality of the planning, feasibility of the execution, and effectiveness as shown by (experimental) effect-evaluations. Almost all large health 
promotion agencies in the Netherlands collaborate in this system. As many interventions are quite difficult to evaluate systematically, quality of planning is often the only relevant criterion, resulting in the label: "theory-based". One exception is the Long Live Love program; a sex education program developed using IM, which received the higher-level label: "effective". Can one judge the quality of the planning that went into an intervention? One can, by systematically evaluating each step as described by the Intervention Mapping protocol50,51. In short, the system wants answers to three questions: 1) What are your objectives and why? 2) What are your planned activities and what does your program comprise of exactly?, and then the crucial question 3) Why do you think that what you do will allow you to reach your objectives? This last question is about what the accreditation system calls the "working principles", and what we call "mechanisms of action" of the behavior change methods, both of which refer to the theoretical process behind the change. The simple but challenging basic question is, therefore, can you explain that your program will achieve your goals, and how? In the case of Long Live Love we could do so, and we also had effect evaluation data to support our claim. In many other cases, such data are not available, but at the same time we still need to justify spending tax payers' money on health promotion activities. And again, the only way to justify that without data on causal effects is to have the program planners explain how they have applied theories correctly.

\section{The Future}

The Future

Is Intervention Mapping - and the focus on correctly applying theories - an idiosyncratic hobby of some (soon-to-be-) retired professors, or is it a sustainable activity? I would argue for the latter. Support for this statement comes in the form of recent research activities that will continue and flourish.

\section{Experimental research and applying theories}

\section{Experimental research and applying theories}

In our department, we carry out a whole range of research activities, varying from basic experimental research to practical applied research. 
We are interested in what determines people's behaviors and how we can influence those behaviors in a more positive direction. Our goal is to better understand behavior and behavior change. We do not focus on one specific type of behavior or one specific type of research method. Our publications cover a wide range of topics including health promotion, reducing discrimination, promoting safety, promoting sustainable environments, as well as addressing other behaviors that are related to societal problems. We not only focus on the individual but also on the environment, for example we study the organizational environment in collaboration with our colleagues in work and organizational psychology. When I started my work at this university in 1984 as professor of health education, I was told to select one specific disease as a focus for my research. It took some time to convince my then-colleagues from the health and medical sciences that applied social psychology has no limits. We are not experts in a specific problem or behavior; we are experts in understanding and changing behavior - any behavior, using behavioral science. We train our Bachelor, Master and Ph.D. students to become behavioral scientists. When I moved to Psychology in 1998, the content of the work stayed the same; the only difference was that the topics were broader than just health. The approach is the same: understanding and changing behavior.

\section{Theory testing research \& theory applying research \\ Theory testing research \& theory applying research} Theories form the basis for our work. In social psychology, we see researchers focusing on developing theories in the behavioral laboratory, others are focusing on validating those theories in the field, and finally we see behavioral scientists applying these theories to solve real life problems. There is no status difference - we need all three types of research. But given this distinction, here in Maastricht we have a history of systematically applying social psychology in a way that is quite unique, both here in the Netherlands and elsewhere. And I include in this observation our colleagues from the Department of Health Promotion who have contributed a lot to this way of doing research and applying theory and evidence to health promotion interventions. I learned a great deal from Henk Wilke during my training in experimental social psychology at Groningen University, in particular about systematic thinking in terms of cause and effect under certain conditions - exactly 
what I mentioned earlier in relation to working principles in behavior change methods. In Groningen I also learned from Peter Veen about the systematic application of theories to try and solve real life problems. It is not a coincidence that my colleagues from Groningen with the same background and training - Hein de Vries, Ree Meertens, Nanne de Vries, Herman Schaalma, Harm Hospers and later Fred Zijlstra - have been so successful at Maastricht University. These inputs, in combination with our collaboration with colleagues from the School of Public Health, University of Texas at Houston - Guy Parcel, Kay Bartholomew and Nell Gottlieb - led to the development of the IM protocol which now holds quite a strong position internationally as a teaching and training text book, and as a research framework and guide for planning behavior change programs. The $4^{\text {th }}$ edition that has just been published was produced by the new generation of IM authors. At the Kay Bartholomew Memorial Event in Houston last February, after the presentation of that new book by Christine Markham, Rob Ruiter and Maria Fernández, Guy Parcel turned to me and said: "Now we can both retire".

\section{When everything fails - a simple answer, please}

Simple answer, please Behavior change is difficult, very difficult. If it was easy, we would not need experts in change. We are asked to help when most other approaches have failed. The simple fact that we are needed indicates how big the challenge is. Nevertheless, I meet many people who find IM too complex, and ask for simpler answers. However, such a request devaluates the expertise of the behavior change expert. The assumption behind this request is that anyone could develop an effective intervention if we could just present the principles of change in an understandable way. That is comparable to asking a surgeon for guidelines on how to do your own appendicitis surgery at home. Of course, there is no reason to make behavior change processes more difficult or more complex than necessary. But it is simply unrealistic to assume that we can explain the complete theoretical foundations of planned behavior change in such a way that everyone can start developing their own effective interventions. That is why we train our students to become Masters in Health \& Social Psychology or Masters in Health Education \& Promotion. As I mentioned earlier, behavioral scientists and their unique expertise are a critical part of an intervention planning team. Maastricht University delivers more than 100 of them every year. 


\section{Research for the future}

\section{Research for the future}

From the past to the future. Carrying out research has not become easier. Funding is a continuous struggle, and decisions about research projects are moving further and further out of our own control. Nevertheless, there are exciting projects underway that will continue to flourish, and there will be more of them in the future.

\section{Long Live Love}

Long Live Love. Long Live Love (LLL) is a sex education program for students in secondary schools, age 14-16. It was developed in the 90 's as a response to the AIDS epidemic. This project was one of the intervention planning examples that served as the basis for the Intervention Mapping protocol $^{2}$. LLL was a collaborative effort between planners from STI/AIDS prevention organizations, school health promotion organizations, and Maastricht University (Herman Schaalma, Jo Reinders en Jos Poelman). The evaluation of this program showed that it produced pronounced effects in terms of both knowledge and attitudes $5^{52}$. Changes in perceived social influences, self-efficacy beliefs, intentions, and sexual risk-taking were smaller, but still significant. Over the years, LLL has been adapted and improved by STI/AIDS NL.

Recently, the $4^{\text {th }}$ edition of LLL was again evaluated and found to be effective ${ }^{53}$. As mentioned earlier, LLL-4 was accredited as 'effective'; the only intervention in that category to receive that label. In addition to improving the program, a systematic implementation intervention for teachers was developed, using IM. Lisette Schutte, Fraukje Mevissen and colleagues analyzed teachers' implementation behaviors and identified common barriers for implementation 54 . They discovered a dilemma; teachers expected that they would encounter some difficulties teaching LLL-4, but at the same time, they were not interested in receiving systematic support. Nevertheless, Lisette Schutte, Marieke van den Borne and colleagues developed an e-coaching intervention for teachers, mainly consisting of role model stories of other teachers about how they handled difficult situations in class55. A systematic evaluation among teachers did not show any effect on teachers' self-efficacy, or on self-reported completeness and fidelity of the LLL-4 implementation. However, and somewhat surprisingly, the evaluation a mong students did show a positive effect of the e-coaching of teachers at the student level. We are still trying to understand what these contradictory outcomes 
mean for the continuation of implementation activities. The teachers who used the e-coaching website were positive about the role model stories, which is at least promising.

\section{Sex Ed for people with intellectual disabilities}

Sex education for people with intellectual disabilities. Dilana Schaafsma, Joke Stoffelen and colleagues used our experience with sex education and IM to develop sex education for a different target group: people with intellectual disabilities (PWID), in collaboration with the Governor Kremers Center. Following the IM protocol, the first step was to evaluate the quality of existing programs ${ }^{56}$. These were evaluated as low-quality, and interestingly enough, the planners agreed with the evaluation because they too wanted better programs. The next step involved identifying factors that paid care staff associated with teaching sex education ${ }^{57}$, followed by a review of effective methods for teaching sex education to $\mathrm{PWID}^{58}$. One explorative study on the experiences of homosexual PWID among males has been completed 59 , while the study among lesbian women is still ongoing ${ }^{60}$. A recent systematic analysis of treatment plans for PWID showed that sex and sex education are almost never mentioned in those plans.

Working with PWID is challenging but exciting. We needed to develop new ways to encourage target group participation, for example by using the nominal group approach ${ }^{61}$. This project will continue and hopefully we will be able to develop a sex education program for PWID that is based on theory and evidence.

\section{Train your Mind: Executive function}

Train your Mind: Training executive function. As mentioned earlier, we want to be behavioral scientists and look beyond the remit of social psychology or health psychology alone. We got the chance to do this by working on a subproject within the MOVARE project. This project is carried out in primary schools, and targets the promotion of health as well as school achievements. Combining social psychology, developmental psychology, clinical psychology and health promotion, Joachim Bervoets and colleagues developed a program, Train your Mind, which focuses primarily on the training of executive function in children. Executive functions (EF's) are higher-order mental control functions comprising of 1) working memory, 2) inhibitory control, and 3) cognitive flexibility ${ }^{62}$. Together, EF's enable us to plan, reason, and solve problems. One might 
feel the urge to indulge in a delicious cup of chocolate \& almond ice cream, but the EF's can override such automatic temptation. Particularly during adolescence, there is a developmental mismatch between the cognitive control system and the socio-emotionally sensitive reward system; adolescents are not stupid, it's just that their EF's are not yet up to task. Research has shown a wide range of long-term correlates for EF's, within the realms of both physical and mental well-being. These include a decreased chance of obesity, a better ability to cope with stress, higher academic achievements, and an increased feeling of self-worth ${ }^{62}$.

Indeed, EF's are very important, and fortunately, EF's can be trained at any time, starting as soon as four years of age. In the Train your Mind project, we focus on children between 9 and 11 years old. The primary goal is to stimulate the development of EF's. The secondary objective of this project is to increase several observable behaviors related to EF's, including academic performance, concentration, emotion-regulation, physical activity, fruit and vegetable consumption, and the avoidance of beverages and snacks rich in sugar (or fat).

We are currently between pretest and posttest in the implementation phase of an RCT involving 7 intervention schools and 6 control schools. What we have already learned is that both primary school children and teachers like the program. Teachers indicate that, while they find the program time consuming, they wish to continue with the program. Obviously, in terms of large scale implementation, we would need to try and integrate more of the program into the standard curriculum. Nevertheless, this is a promising project, with all kinds of potential spinoffs.

\section{Focus on Strength}

Psychology and biology: Focus on Strength. Real interdisciplinary research is rare. However, "Interdisciplinary research makes a major contribution to scientific innovation, leads to greater breadth and depth in individual disciplines, generates cross-disciplinary knowledge, and often plays a vital role in analyzing the major challenges facing society" 63 . Gill ten Hoor has completed both a Masters in Biology and a Masters in Psychology and surprised us with the following question: "Do you know that youngsters who are overweight are also stronger than most of their peers?" We did not know that. His next question was: "Do you know that strength training promotes a healthier body composition which is more important 
than BMI?" No, we did not know that either. This cross-disciplinary knowledge led to the project Focus on Strength ('de Kracht van Kracht') being implemented in the first years of secondary school education, funded by ZonMw. Due to the fact that physical education (PE) classes are usually filled with aerobic exercises, overweight youngsters often perform badly. Even when strength is involved, such as when climbing a rope, their weight is still a barrier. Gill ten Hoor and colleagues ${ }^{64,65}$ introduced exercises focusing on pure strength that can be integrated into PE classes, comprising 30\% of class time. Overweight youngsters are better in these kinds of exercises than most of their peers, providing short-term reinforcement. Moreover, performing these exercises will lead to a better body composition. This has the advantage of being something that can be measured (and used to provide feedback) in the short-term, as well as having longer-term positive effects. In addition to the strength training, students participate in Motivational Interviewing training, with the aim of guiding and helping them to exercise more in their life outside school. Overweight youngsters often see PE and sports as a punishment; in this project we hope to let them experience that exercises focusing on pure strength can be rewarding 64,65 .

We are currently between pretest and posttest in an RCT involving 6 intervention schools and 7 control schools. Our observations indicate that the PE teachers are enthusiastic about the strength exercises, and there is anecdotal evidence for positive effects on students. We will see what the effects measures show. But we have certainly learned that real interdisciplinary research "makes a major contribution to scientific innovation, leads to greater breadth and depth in individual disciplines, generates cross-disciplinary knowledge, and often plays a vital role in analyzing the major challenges facing society" 63 . 


\section{Epilogue}

\section{Epilogue}

As I mentioned before, individuals live in a socio-ecological environment. So do I. Looking back, I grew up in a family where prosocial behavior and a sense of reason were so self-evident, that I only much later realized how unusual that was. I chose social psychology for completely the wrong reasons, but it turned out to be a wonderful choice. That I was selected as the best candidate for a full-professorship in Maastricht was the result of a unique combination of circumstances outside my control. The collaboration with the Center of Health Promotion of the School of Public Health in Houston had been decided before I started in Maastricht, but has been one of the best things that has happened to me both on a professional and personal level. I am certainly aware of the fact that I have had a lot of chances and much support. I learned from my teachers, colleagues and students, and I thank you all for that. I hope that I have been able to teach others as well, and give them the same chances and support that I received myself. What I am sure of is that the good work will continue.

Thank you. 


\section{References}

1. van Heerden, J., 1993. De jaarlijke Al Capone lezing. In: J. van Heerden, Van oude en nieuwe trauma's (pp.52-55). Amsterdam: Prometeus.

2. Schaalma, H. \& Kok, G., 2011. Case study 3: A school HIV-prevention program in the Netherlands. Case study on the companion site for Bartholomew et al. (2011). http://bcs.wiley.com/he-bcs/Books?action $=$ resource $\&$ bcsld $=6279 \&$ item $I d=0470528516 \&$ resourceld $=23357$

3. Schaalma, H.P., Abraham, C., Gillmore, M.R., \& Kok, G., 2004. Sex education as health promotion: What does it take? Archives of Sexual Behavior, 33, 259-269.

4. Ruiter, R.A.C., Kessels, L.T., Peters, G-J.Y. \& Kok, G., 2014. Sixty years of fear appeal research: Current state of the evidence. International Journal of Psychology, 49, 63-70. DOI: 10.1002/ijop.12042

5. Peters, G-J.Y., Ruiter, R.A.C., \& Kok, G., 2013. Threatening communication: A critical re-analysis and a revised meta-analytic test of fear appeal theory. Health Psychology Review, 7 (sup1), S8-S31. DOI: 10.1080/17437199.2012.703527

6. Kessels, L.T.E., Ruiter, R.A.C., Wouters, L., \& Jansma, B.M., 2014. Neuroscientific evidence for defensive avoidance of fear appeals. International Journal of Psychology, 49, 80-88.

7. Kok, G., Ruiter, R., Van den Hoek, K., Schaalma, H.P. \& De Vries, N.K., 2007. Waarschuwingsplaatjes op tabaksverpakking zijn niet effectief. TSG, Tijdschrift voor Gezondheidswetenschappen, 85, 133-135.

8. Peters, G-J., Ruiter, R.A.C., Kessels, L. \& Kok, G., 2012. Angstaanjagende voorlichting: niet effectief, maar desondanks wordt het nog gebruikt. TSG, Tijdschrift voor Gezondheidswetenschappen, 91, 15-18.

9. Kok, G., Peters, G-J., Ruiter, R., Kessels, L., ten Hoor G. \& Mevissen, F., 2013. Zijn er alternatieven voor angstaanjagende voorlichting? Gebruik Intervention Mapping! TSG, Tijdschrift voor Gezondheidswetenschappen, 91, 145-149.

10. Kok, G., Peters, G-J.Y. \& Ruiter, R.A.C., 2013. Enge plaatjes op sigarettenpakjes niet zinvol. Nederlands Tijdschrift voor Geneeskunde, 157, A6167.

11. Staatscourant, nr. 129, Maandag 9 juli, 2007: Bangmakerij helpt niet.

12. ten Hoor, G.A., Peters, G-J.Y., Kalagi, J. de Groot, L., Grootjans, K., Huschens, A., Kohninger, C., Kolgen, L., Pelssers, I., Schutt, T., Thomas, S., Ruiter R.A.C. \& Kok, G., 2012. Reactions to threatening health messages. BMC Public Health, 12, 1011. doi:10.1186/1471-2458-12-1011 
13. Brown, S.L. \& Smith, E.Z., 2007. The inhibitory effect of a distressing anti-smoking message on risk perceptions in smokers. Psychology \& Health, 22, 255-268.

14. Brown, S.L. \& Locker, E., 2009. Defensive responses to an emotive antialcohol message. Psychology \& Health, 24, 517-528.

15. de Vries, H., Backbier, E., Dijkstra, M., Van Breukelen, G., Parcel, G. \& Kok, G., 1994. A Dutch social influence smoking prevention approach for vocational school students. Health Education Research, 9, 365-374.

16. Mudde, A.N., \& De Vries, H., 1999. The reach and effectiveness of a national mass media-led smoking cessation campaign in The Netherlands. American Journal of Public Health, 89, 346-350.

17. Bakker, M.J., Mullen, P.D., de Vries, H., \& van Breukelen, G., 2003. Feasibility of implementation of a Dutch smoking cessation and relapse prevention protocol for pregnant women. Patient Education and Counseling, 49, 35-43.

18. Dijkstra, M., Mesters, I., De Vries, H., Van Breukelen, G., \& Parcel, G.S., 1999. Effectiveness of a social influence approach and boosters to smoking prevention. Health Education Research, 14, 791-802.

19. Dijkstra, A., De Vries, H., \& Bakker, M., 1996. Pros and cons of quitting, self-efficacy, and the stages of change in smoking cessation. Journal of Consulting and Clinical Psychology, 64, 758-763.

20. Willemsen, M.C., de Vries, H., van Breukelen, G., \& Genders, R., 1998. Long-term effectiveness of two Dutch work site smoking cessation programs. Health Education \& Behavior, 25, 418-435.

21. Dalum, P., Paludan-Müller, G., Engholm, H. \& Kok, G., 2012. A cluster randomised controlled trial of an adolescent smoking cessation intervention: Short and long-term effects. Scandinavian Journal of Public Health, 40, 167-176. DOI: 10.1177/1403494811435488

22. http://www.who.int/fctc/guidelines/adopted/article_11/en/, http:// www.who.int/fctc/guidelines/adopted/eleven/en/.

23. Hammond, D., Fong, G.T., McDonald, P.W., Brown, K.S. \& Cameron, R., 2004. Graphic Canadian cigarette warnings labels and adverse outcomes: Evidence from Canadian smokers. American Journal of Public Health, 94, 1442-1445.

24. Ruiter, R.A.C. \& Kok, G., 2005. Saying is not (always) doing: cigarette warning labels are useless. European Journal of Public Health, 15, 329330.

25. Hammond, D., Fong, G.T., McDonald, P.W., Brown, K.S. \& Cameron, R., 2006. Showing leads to doing: graphic warning labels are an effective public health policy. European Journal of Public Health, 16, 223. 
26. Ruiter, R.A.C. \& Kok, G., 2006. Showing leads to doing, but doing what? The need for experimental pilot testing (Response to: Hammond et al.). European Journal of Public Health, 16, 225.

27. Cook, T. D. \& Campbell, D. T., 1979. Quasi-experimentation: Design and analysis issues for filed settings. Houghton Mifflin Company: Boston.

28. Witte K, Allen M., 2000. A meta-analysis of fear appeals: Implications for effective public health campaigns. Health Education \& Behavior, 27, 591-615.

29. Condiotte, M. M., \& Lichtenstein, E., 1981. Self-efficacy and relapse in smoking cessation programs. Journal of Consulting and Clinical Psychology, 49, 648.

30. Wong, V.C., Wing, C., Steiner, P.M., Wong, M., \& Cook, T.D., 2012. Research designs for program evaluation. In W. Velicer \& J. Schinka (Eds.), Handbook of Psychology: Research Methods in Psychology (2nd Ed., pp. 316-341). Hoboken, NJ: Wiley and Sons.

31. https://en.wikipedia.org/wiki/Theory

32. Bartholomew, L. K., Markham, C. M., Ruiter, R. A. C., Fernàndez, M. E., Kok, G., \& Parcel, G. S., 2016. Planning health promotion programs: An Intervention Mapping approach, 4th edition. Hoboken, NJ: Wiley. ISBN-13: 978-1119035497

33. Kok, G. \& Ruiter, R.A.C. , 2014. Who has the authority to change a theory? Everyone! A commentary on Head and Noar. Health Psychology Review, 8, 61-64. DOI: 10.1080/17437199.2013.840955

34.Dawkins, R., 1996. River out of Eden: A Darwinian view of life. New York: Harper Collins Publishers.

35. Pasick, R.J., Burke, N.J., Barker, J.C., Joseph, G., Bird, J.A., Otero-Sabogal, R., Tuason, N. Stewart, S.L., Rakowski, W., Clark, M.A., Washington, P.K., \& Guerra, C., 2009. Behavioral theory in a diverse society: Like a compass on Mars. Health Education \& Behavior, 36(S5), 11S-35S.

36. Reddy, P., Meyer-Weitz, A., Van den Borne, B. \& Kok, G., 1999. STDrelated knowledge, beliefs, and attitudes of Xhosa-speaking patients attending STD primary health-care clinics in South Africa. International Journal of STD and AIDS, 10, 392-400.

37. Kaaya, S. F., Flisher, A. J., Mbwambo, J. K., Schaalma, H., Aarø, L. E., \& Klepp, K. I., 2002. Review article: a review of studies of sexual behaviour of school students in sub-Saharan Africa. Scandinavian Journal of Public Health, 30, 148-160.

38. Al-Iryani, B., Basaleem, H., Al-Sakkaf, K., Crutzen, R., Kok, G. \& van den Borne, B., 2011. Evaluation of a school-based HIV prevention intervention among Yemeni adolescents. BMC Public Health, 11: 279. DOI: 10.1186/1471-2458-11-279 
39. Hinduan, Z. R., Kesumah, N., Iskandar, Z., van Crevel, R., Alisjahbana, B., \& Hospers, H. J., 2009. Characteristics of subjects counseled and tested for HIV in an Indonesian hospital; factors associated with HIVstatus and CD4 cell-count. Acta Medica Indonesiana, 41(Suppl 1), 12 Á7.

4O. Sialubanje, C., Massar, K., Hamer, D.H., \& Ruiter, R.A.C., 2014. Understanding the psychosocial and environmental factors and barriers affecting utilization of maternal healthcare services in Kalomo, Zambia; a qualitative study. Health Education Research, 29, 521-532.

41. Kok, G., Gottlieb, N. H., Peters, G.-J. Y., Mullen, P. D., Parcel, G. S., Ruiter, R. A. C., Fernández, M. E., Markham, C., \& Bartholomew, L. K., 2015. A taxonomy of behavior change methods; an Intervention Mapping approach. Health Psychology Review, online. DOI:10.1080/17437199.2 015.1077155

42. Peters, G-J.Y. \& Kok, G., 2016. All models are wrong, but some are useful: How to celebrate variability of persons, variability of theories, and systematic behaviour change application and research (A commentary on Ogden, 2016). Health Psychology Review, accepted for publication.

43. Buunk, A. P., \& Van Vugt, M., 2013. Applying social psychology: From problems to solutions (2nd Ed.). London, United Kingdom: Sage.

44. Kelder, S., Hoelscher, D., \& Perry, C.L., 2015. How individuals, environments and health behaviors interact: Social Cognitive Theory. In K. Glanz, B.K. Rimer, \& K. Viswanath (Eds.), Health behavior: Theory, research, and practice (5th Ed., pp. 159-182). San Francisco, CA, US: John Wiley \& Sons.

45. Latham, G. P., \& Locke, E. A., 2007. New developments in and directions for goal-setting research. European Psychologist, 12, 290300. doi:10.1027/1016-9040.12.4.290

46. Hagger, M.S., Luszczynska, A., de Wit, J., et al., 2016. Implementation intentions and planning interventions in health psychology: Recommendations from the Synergy expert group for research and practice. Psychology \& Health, online. DOI: 10.1080/08870446.2016.1146719

47. Peters, G-J.Y. Ruiter, R.A.C. \& Kok G., 2014. Threatening communication: A qualitative study of fear appeal effectiveness beliefs among intervention developers, policy makers, politicians, scientists, and advertising professionals. International Journal of Psychology, 49, 71-79. DOI: 10.1002/ijop.12000 
48. Peters, G-J Y., de Bruin, M., \& Crutzen, R., 2015. Everything should be as simple as possible, but no simpler: Towards a protocol for accumulating evidence regarding the active content of health behaviour change interventions. Health Psychology Review, 9, 1-14. doi:10.1080/17437199.2013.848409

49. de Bruin, M., Crutzen, R., \& Peters, G-J.Y., 2015. Everything should be as simple as possible, but this will still be complex: A reply to various commentaries on IPEBA. Health Psychology Review, 9, 38-41. doi:10.1 o80/17437199.2014.981833

50. Godin G., Gagnon H., Alary M., Levy J. J. \& Otis J., 2007. The degree of planning: an indicator of the potential success of health education programs. Promotion and Education 9, 138-142.

51. Schaafsma, D., Stoffelen, J.M.T., Kok, G. \& Curfs, L.M.G., 2013. Exploring the development of existing sex education programmes for people with intellectual disabilities: an Intervention Mapping approach. Journal of Applied Research in Intellectual Disabilities, 26, 157-166.

52. Schaalma, H., Kok, G., Bosker, R., Parcel, G., Peters, L., Poelman, J. \& Reinders, J., 1996. Planned development and evaluation of AIDS/STD education for secondary school students in the Netherlands: Short term effects. Health Education Quarterly, 23, 469-487.

53. Hofstetter, H., Peters, L. W. H., Meijer, S., Van Keulen, H. M., Schutte, L., \& van Empelen, P., 2014. Evaluation of the effectiveness and implementation of the sexual health program Long Live Love IV. European Health Psychologist, 16(S), 489 (Abstract).

54. Schutte, L., Meertens, R., Mevissen, F., Schaalma, H., Meijer,S. \& Kok, G., 2014. Long Live Love: The implementation of a school-based sexeducation program in the Netherlands. Health Education Research, 29, 583-597. DOI:10.1093/her/cyuo21

55. Schutte, L., van den Borne, M., , Meijer, S., Kok, G. \& Mevissen, F. 2016. Innovatively supporting teachers' implementation of schoolbased sex education; an online coaching intervention from problem to solution. Journal of Medical Internet Research, accepted for publication.

56. Schaafsma, D., Stoffelen, J.M.T., Kok, G. \& Curfs, L.M.G., 2013. Exploring the development of existing sex education programmes for people with intellectual disabilities; an Intervention Mapping approach. Journal of Applied Research in Intellectual Disabilities, 26, 157-166. 
57. Schaafsma, D., Kok, G., Stoffelen, J. M., van Doorn, P., \& Curfs, L. M., 2014. Identifying the important factors associated with teaching sex education to people with intellectual disability: A crosssectional survey among paid care staff. Journal of Intellectual and Developmental Disability, 39, 157-166. DOI:10.3109/13668250.2014.89 9566

58. Schaafsma, D., Kok, G., Stoffelen, J. \& Curfs, L., 2015. Identifying effective methods for teaching sex education to people with intellectual disabilities; a systematic review. Journal of Sex Research, 52, 412-432.

59. Stoffelen, J., Kok, G., Hospers, H. \& Curfs, L., 2012. Homosexuality among people with a mild intellectual disability; an explorative study on the lived experiences of homosexual people in the Netherlands with a mild intellectual disability. Journal of Intellectual Disability Research, 57, 257-267.

6o. Stoffelen, J.M.T., Schaafsma, D., Kok, G. \& Curfs, L.M.G., 2014. Women who love: An explorative study on the lived experiences of lesbian and bisexual women with a mild intellectual disability in The Netherlands. Journal of Applied Research in Intellectual Disabilities 27, 362-363 (Abstract).

61. Stoffelen, J.M.T., Schaafsma, D., Kok, G., Curfs, L.M.G., 2012. Talking about sex with people with intellectual disabilities. Journal of Intellectual Disability Research, 56, 809-809 (Abstract).

62. Diamond, A., 2013. Executive functions. Annual Review of Psychology, $64,135-168$.

63. De Jonge Akademie, 2015. Grensverleggend: Kansen en belemmeringen voor interdisciplinair onderzoek. Amsterdam: KNAW.

64. ten Hoor, G.S., Plasqui, G., Schols, A.M.W.J. \& Kok, G., 2014. Combating adolescent obesity: An integrated physiological and psychological perspective. Current Opinion in Clinical and Nutrition Metabolic Care, 17: 521-524.

65. ten Hoor, G.A., Plasqui, G., Ruiter, R.A.C., Kremers, S.P.J., Schols A. \& Kok, G., 2015. A new direction in Psychology and Health: Resistance exercise training for obese children and adolescents. Psychology \& Health, 31, 1-8. DOI:10.1080/08870446.2015.1070158 


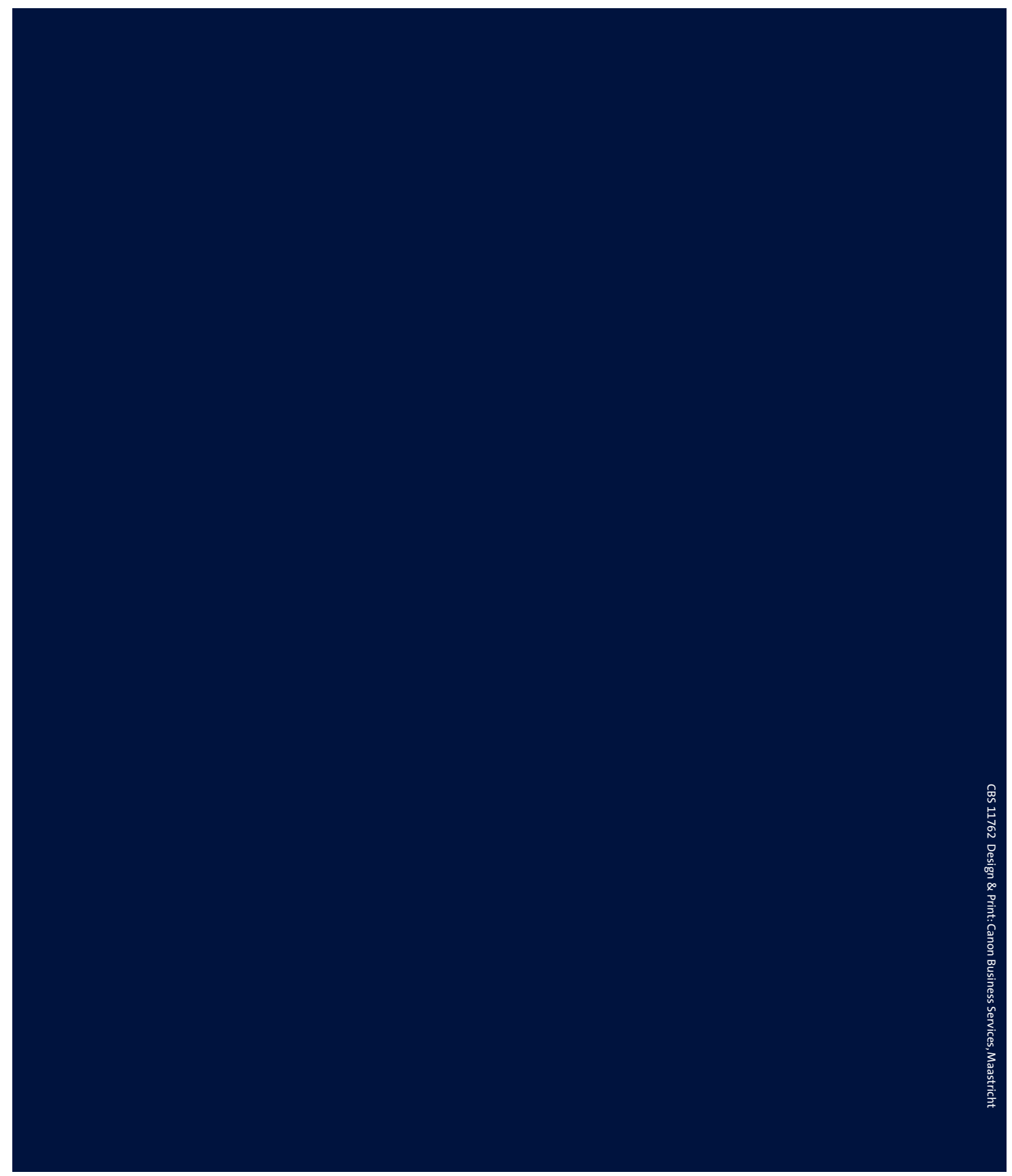

